\title{
Post Septoplasty Complications and Its Relationship with Allergic Rhinitis: Comparative Study
}

\author{
Abdulwahid S AL Qahtani ${ }^{1 *}$, Rmzi M Dagriri², Ahmad M Alrasheed ${ }^{1}$, Ahmad A Etwadi $^{3}$, Khalid A Al Qahtani ${ }^{4}$, \\ Montasir Junaid ${ }^{1}$ and Sadaf Qadeer Ahmed ${ }^{5}$
}

${ }^{1}$ Armed Forces Hospital, Southern Region, Khamis Mushait, Saudi Arabia

${ }^{2}$ Armed Forces Hospital, Jazan, Saudi Arabia

${ }^{3,4}$ General Hospital of Khamis Mushait, Saudi Arabia

${ }^{5}$ Sir Syed College of Medical Sciences for Girls, Karachi, Pakistan

*Corresponding author: Abdulwahid S AL Qahtani, Armed Forces Hospital, Southern Region, Khamis Mushait, Saudi Arabia

\begin{abstract}
Background: Allergic rhinitis (AR) is characterized by inflammation in the nose as the immune system respond to inhaled allergens in the air. Signs and symptoms include a runny, stuffy red and itchy nose, sneezing with watery eyes, and swelling around the eyes A deviated septum mostly is asymptomatic, but sometimes may be presented by difficulty breathing through the nose, nasal congestion, sinus infections, nosebleeds, sleep apnea, headache, and postnasal drip. Septoplasty is the main surgical intervention for patients with deviated nasal septum to relieve nasal obstruction. While Allergic rhinitis is mainly treated with anti-allergy medicine.

Aim: To detect the incidence of post-septoplasty complications among patients with deviated nasal septum and Identify the correlation between the allergic rhinitis and post-operative complications as compared with non-allergic patients.

Methodology: A retrospective Electronic record-based study was conducted including all patients with clinically diagnosed as deviated nasal septum and undergone surgical intervention at Khamis Mushait General Hospital. Data extracted included patient's demographic data, recorded post-operative complications and history of having allergic rhinitis.

Results: The study included a total sample of 93 patients; Nasal obstruction was the most frequent complaint among patients. As for post-operative complications, nearly one third of the cases had nasal obstruction followed by external nasal deformity, and smell disturbance. Nasal obstruction was diagnosed higher among patients with allergic rhinitis ( $\mathrm{P}=.142)$. External nasal deformity was recorded among $6.2 \%$ of the cases with allergic rhinitis compared to $3.6 \%$ of others without allergic rhinitis. Regarding smell disturbance, it was reported among $13.8 \%$ of the patients with allergic rhinitis compared to $3.6 \%$ of those without allergic rhinitis.

Conclusions: The study revealed that post-septoplasty nasal obstruction as a complication is most common with similar incidence rate in both allergic and non-allergic rhinitis patient groups while septal hematoma was least common. All post septoplasty complications except nasal obstruction were found to be significantly higher among allergic rhinitis cases.
\end{abstract}

Keywords: Allergic rhinitis, septoplasty, surgical intervention, deviated septum, complications, nasal allergy

Abbreviations: DNS: Deviated Nasal Septum; AR: Allergic Rhinitis; CSF: Cerebrospinal Fluid 


\section{Background}

Allergic rhinitis (AR) is a prevalent disease reported among all ages, with the highest percentage in the teenage years [1]. It affects $10-20 \%$ of the entire population, hence causing AR to be the one of the most chronic non-communicable disorder [2]. It is mostly under diagnosed or even misdiagnosed, and mistreated, causing harmful health related effects [3]. Allergic rhinitis is characterized by inflammation in the nose as the immune system respond to inhaled allergens in the air [4]. Signs and symptoms include a runny or stuffy red and itchy nose, sneezing with watery eyes, and swelling around the eyes [5]. Symptoms are rapidly emerging with allergen exposure and associated with poor sleep hygiene and work ability [6,7]. Mostly, allergic rhinitis is usually associated with asthma, allergic conjunctivitis, or atopic dermatitis $[8,9]$. Septoplasty is the main surgical intervention for patients with deviated nasal septum to relieve nasal obstruction [10-14]. In some cases, additional turbinate surgery is performed. Most of studies concerned with post-operative improvement reported that about $60 \%$ of patients undergoing septoplasty showed an improvement in nasal breathing [15]. Septal perforation and septal hematoma are recorded as complications along with decreased sense of smell [16]. Temporary hypoesthesia of the front upper teeth after surgery is not rare [17]. The post-operative complications intensity or nature may be affected by whether the patients had allergic rhinitis (AR) or not as AR may aggravates the nasal obstruction and bleeding tendency [18]. The current study is aimed at revealing the incidence of post septoplasty complications among both allergic and non-allergic rhinitis patient groups.

\section{Methodology}

A retrospective Electronic record-based study was conducted including all patients with clinically diagnosed nasal septum deviation and underwent surgical intervention (Septoplasty) at Khamis Mushait General Hospital during the period from January 2017 to end of May 2019. Apart from collecting Electronic data the patients were also contacted via telephone to take verbal consent to use their Electronic data and inquire about allergic symptoms if already not mentioned in their record. Patients were excluded if they had missing Electronic files, failure to give verbal consent to participate (Telephonic), failure to contact the patient, or had septoplasty as part of another procedure or along with another surgery. After reviewing the medical files, the data was collected on a pre-structured questionnaire. Data so collected included patient's demographics and post-operative complications for the surgery such as nasal obstruction, nasal deformity, loss of smell sensation, and others if any.

\section{Data analysis}

The collected data was coded, and statistical software IBM SPSS version 22 was used to analyze it. The given graphs were constructed using Microsoft excel software. All statistical analysis was done using two tailed tests and alpha error of 0.05. P value less than or equal to 0.05 was significant. Frequency in percent \& distribution of the different collected variables including patient's demographic data and post-operative complications were analyzed. Crosstabulation was used to show the post-operative complications distribution in relation patients' history of having allergic rhinitis using exact probability tests.

\section{Results}

The study included a total sample of 93 patients out of 120 cases, sixty-five (69.9\%) of the patients aged less than 30 years and $60.2 \%$ were males. Young aged persons constituted $70.8 \%$ of cases with allergic rhinitis compared to $67.9 \%$ of cases without. Also, females were $44.6 \%$ of cases with allergic rhinitis while $28.6 \%$ of those without allergic cases (Table 1). As for post-operative complications, figure 1 demonstrates that $32 \%$ of the cases had nasal obstruction followed by external nasal deformity (17\%), smell disturbance (11\%), dental anesthesia (10\%), infection (10\%), septal perforation(6\%),and nasal bleeding(5\%). Considering distribution of the complications according to the patients with history of allergic rhinitis (Table 2), nasal obstruction was diagnosed among $32.3 \%$ of the allergic patients compared to $32.1 \%$ of cases with no allergic history $(\mathrm{P}=0.988)$. External nasal deformity was recorded among $6.2 \%$ of the cases with AR compared to $3.6 \%$ of others without AR $(\mathrm{P}=0.613)$ Septal perforation was recorded among $7.7 \%$ of the cases with AR in comparison to $3.6 \%$ of the cases without AR $(\mathrm{P}=0.458)$. Post-surgical infection with septal abscess was diagnosed among $10.8 \%$ of the AR patients compared to $7.1 \%$ of the other group $(\mathrm{P}=0.587)$. Regarding smell disturbance, it was reported among $13.8 \%$ of the patients with AR compared to $3.6 \%$ of those without $\mathrm{AR}(\mathrm{P}=0.142)$. Watery nasal discharge was diagnosed for $4.6 \%$ of the patients with AR in comparison to $3.6 \%$ of those who were free of AR history ( $\mathrm{P}=0.820)$. Dental anaesthesia was complained by $12.3 \%$ of AR patients compared to $3.6 \%$ of others without AR ( $\mathrm{P}=0.191)$. Lastly, Septal hematoma was recorded one case with AR while was not recorded among any case without history of AR ( $\mathrm{P}=0.509)$ (Figure 1). 


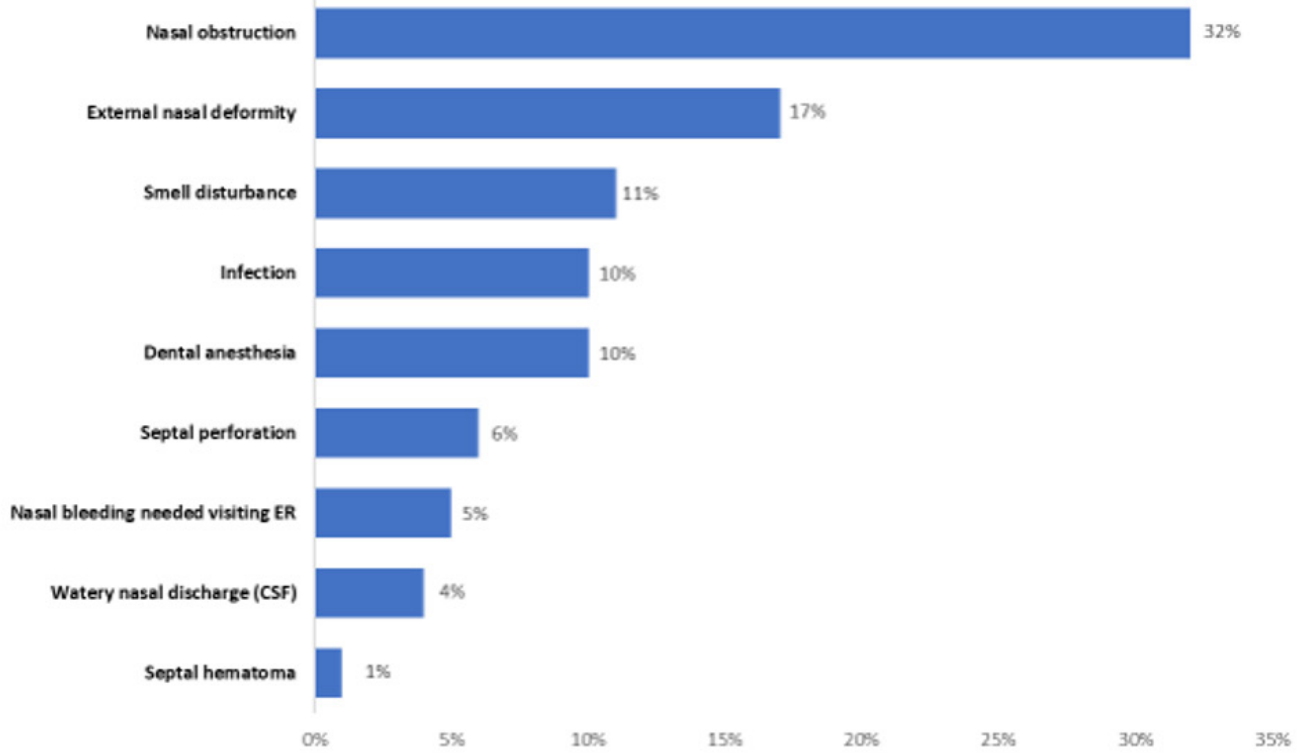

Figure 1: Post-operative complications among patients undergone septoplasty in Khamis Mushait general Hospital.

Table 1: Bio-demographic data of patients with nasal septum deviation in relation to history of allergic rhinitis in Khamis Mushait general Hospital.

\begin{tabular}{|c|c|c|c|c|c|c|}
\hline \multirow{3}{*}{ Personal data } & \multirow{3}{*}{ Total (\%) } & \multicolumn{4}{|c|}{ History of Allergic Rhinitis } & \multirow{3}{*}{ P-value } \\
\hline & & \multicolumn{2}{|c|}{ No } & \multicolumn{2}{|c|}{ Yes } & \\
\hline & & No & $\%$ & No & $\%$ & \\
\hline \multicolumn{7}{|c|}{ Age in Years } \\
\hline$<30$ years & $65(69.9 \%)$ & 19 & $67.90 \%$ & 46 & $70.80 \%$ & 0.779 \\
\hline$>30$ years & $28(30.1 \%)$ & 9 & $32.10 \%$ & 19 & $29.20 \%$ & \\
\hline \multicolumn{7}{|c|}{ Gender } \\
\hline Male & $56(60.2 \%)$ & 20 & $71.40 \%$ & 36 & $55.40 \%$ & 0.147 \\
\hline Female & 37 (39.8\%) & 8 & $28.60 \%$ & 29 & $44.60 \%$ & \\
\hline
\end{tabular}

Table 2: Post-operative complications among patients undergone septoplasty according to history of allergic rhinitis, Khamis Mushait general Hospital.

\begin{tabular}{|c|c|c|c|c|c|}
\hline \multirow{3}{*}{ Post-Operative Complications } & \multicolumn{4}{|c|}{ Allergic Rhinitis } & \multirow{3}{*}{ P-value } \\
\hline & \multicolumn{2}{|c|}{ No } & \multicolumn{2}{|c|}{ Yes } & \\
\hline & No & $\%$ & No & $\%$ & \\
\hline Nasal obstruction & 9 & $32.10 \%$ & 21 & $32.30 \%$ & 0.988 \\
\hline Nasal bleeding needed visiting ER & 1 & $3.60 \%$ & 4 & $6.20 \%$ & 0.613 \\
\hline Septal perforation & 1 & $3.60 \%$ & 5 & $7.70 \%$ & 0.458 \\
\hline External nasal deformity & 4 & $14.30 \%$ & 12 & $18.50 \%$ & 0.625 \\
\hline Infection & 2 & $7.10 \%$ & 7 & $10.80 \%$ & 0.587 \\
\hline Smell disturbance & 1 & $3.60 \%$ & 9 & $13.80 \%$ & 0.142 \\
\hline Watery nasal discharge (CSF) & 1 & $3.60 \%$ & 3 & $4.60 \%$ & 0.82 \\
\hline Dental anaesthesia & 1 & $3.60 \%$ & 8 & $12.30 \%$ & 0.191 \\
\hline Septal hematoma & 0 & $0.00 \%$ & 1 & $1.50 \%$ & 0.509 \\
\hline
\end{tabular}




\section{Discussion}

High number of deviated nasal septum patients have concurrent allergic rhinitis. Even though the conditions are not similar, for patients with allergies or a deviated septum, there are some similarities. For example, both diseases may lead to sinus infection, both mimic the signs and symptoms of common cold. Allergic rhinitis by the way of triggering allergic response to airborne allergens while deviated septum can also have nasal swelling and increased mucus, leading to same $[19,20]$. A significant deviated nasal septum causes blockage on one side of the nose and reduces airflow, causing difficulty breathing [21]. On diagnosing nasal septum deviation, medical management using topical nasal steroids, antihistamines, and decongestants as applied for the nasal mucosa is typically attempted first. In case of failure, a surgical intervention to correct the underlying septal deformity is the second line [22-30]. The current study aims to clarify the correlation between the allergic rhinitis and post septoplasty complications as compared with non-allergic patients that will reveal either significant or non- significant impact or difference. The study revealed that nasal obstruction was the most reported post septoplasty complication with close incidence in both allergic rhinitis and non-allergic rhinitis groups [31,32]. This is against what we expected that the postoperative nasal obstruction will be higher in AR patients as a result from AR itself. this observation is supported by another study which was done in our region (South of Saudi Arabia) and found positive outcome of septoplasty for those AR patients with nasal obstruction postoperatively [33]. The second most common postoperative complication is external nasal deformity in both groups, slightly higher among AR patients' group. The least complication is similar in both groups which is septal hematoma. The other postoperative complications are ordered from more to less common among the patients with AR as following, smell disturbance, dental anaesthesia, infection, perforation, nasal bleeding then watery discharge. While among the patients without AR are infection, nasal bleeding, smell disturbance, dental anaesthesia, perforation then watery discharge which are having the same incidence rate. All post septoplasty surgical complications that were recorded higher among allergic rhinitis cases except nasal obstruction but the higher rate among AR cases was insignificantly different than other for the sample in total.

\section{Conclusions}

In conclusion, the study revealed that postoperative nasal obstruction complication is the most one with similar incidence rate in both allergic and non-allergic rhinitis patient groups while the least one is septal hematoma. The other postoperative complications are different in both groups regarding the commonness. All post septoplasty complications except nasal obstruction are slightly higher among allergic rhinitis cases. Our study opens more query and understanding to the pathophysiology of allergic rhinitis and its impact on the post-surgical outcomes.

\section{References}

1. Greiner AN, Hellings PW, Rotiroti G, Scadding GK (2011) Allergic rhinitis. The Lancet 378(9809): 2112-2122.

2. Öçal R, Muluk NB, Mullol J (2020) Epidemiology of Allergic Rhinitis. In All Around the Nose. Springer pp. 297-301.

3. Maurer M, Zuberbier T (2007) Undertreatment of rhinitis symptoms in Europe: findings from a cross-sectional questionnaire survey. Allergy 62(9): 1057-1063.

4. Rondón C, Campo P, Togias A, Fokkens WJ, Durham SR, et al. (2012) Local allergic rhinitis: concept, pathophysiology, and management. Journal of Allergy and Clinical Immunology 129(6): 1460-1467.

5. Wheatley LM, Togias A (2015) Clinical practice. Allergic rhinitis. The New England Journal of Medicine 372 (5): 456-463.

6. Covar Ronina (2018) Allergic Disorders. Current Diagnosis \& Treatment, Pediatrics, $24^{\text {th }}$ Edn, McGraw-Hill, NY, USA Chapter 38.

7. Meltzer EO (2016) Allergic rhinitis: burden of illness, quality of life, comorbidities, and control. Immunol Allergy Clin North Am 36(2): 235248.

8. Parisi CA, Eymann A, Puga MC, Petriz NA, De Gennaro M (2018) Allergic Rhinitis and Other Atopic Diseases in Children with Attention Deficit Hyperactivity Disorder. Current Treatment Options in Allergy 5(2): 247255.

9. Koh YY, Kim CK (2003) The development of asthma in patients with allergic rhinitis. Current opinion in allergy and clinical immunology 3(3): 159-164.

10. Jessen M, Ivarsson A, Malm L (1989) Nasal airway resistance and symptoms after functional septoplasty: comparison of findings at 9 months and 9 years. Clin Otolaryngol Allied Sci 14(3): 231-234.

11. Konstantinidis I, Triaridis S, Triaridis A, Karagiannidis K, Kontzoglou G (2005) Long term results following nasal septal surgery: focus on patients' satisfaction. Auris nasus larynx 32(4): 369-374.

12. Pedersen L, Schiöler L, Holmberg K, Ahlström Emanuelsson C, Hellgren J (2018) Age and unplanned postoperative visits predict outcome after septoplasty: a national Swedish register study. International journal of otolaryngology 2018(2): 1-6.

13. Shrestha KK, Joshi RR, Rijal AS, Dhungana A, Maharjan S (2019) Assessment of septoplasty outcome using Nasal Obstruction Symptom Evaluation scale. Nepal Medical College Journal 21(2): 142-146.

14. Rambabu P, Rao SS, KSRC TL (2018) Comparative Study of Complications in Endoscopic Septoplasty Versus Conventional Septoplasty. J Evid Based Med Health 5(44): 3080-3083.

15. Valsamidis K, Printza A, Titelis K, Constantinidis J, Triaridis S (2019) Olfaction and quality of life in patients with nasal septal deviation treated with septoplasty. American Journal of otolaryngology 40(5): 747-754.

16. Tsang CL, Nguyen T, Sivesind T, Cervin A (2018) Long-term patientrelated outcome measures of septoplasty: a systematic review. European Archives of Oto-Rhino-Laryngology 275(5): 1039-1048.

17. Gray LP (1978) Deviated nasal septum incidence and etiology. Annals of Otology, Rhinology \& Laryngology 87(2): 3-20.

18. Gillman GS, Staltari GV, Chang YF, Mattos JL (2019) A Prospective Study of Outcomes of Septoplasty with Turbinate Reductions in Patients with Allergic Rhinitis. Otolaryngology-Head and Neck Surgery 160(6): 11181123. 
19. Karatzanis AD, Fragiadakis G, Moshandrea J, Zenk J, Iro H, et al. (2009) Septoplasty outcome in patients with and without allergic rhinitis. Rhinology 47(4): 444-449.

20. Ahn JC, Kim JW, Lee CH, Rhee CS (2016) Prevalence and risk factors of chronic rhinosinusitus, allergic rhinitis, and nasal septal deviation: results of the Korean National Health and Nutrition Survey 2008-2012. JAMA Otolaryngology-Head \& Neck Surgery 142(2): 162-167.

21. Bhattacharyya N (2010) Ambulatory sinus and nasal surgery in the United States: demographics and perioperative outcomes. Laryngoscope 120(3): 635-638.

22. Akoglu E, Karazincir S, Balci A, Okuyucu S, Sumbas H, et al. (2007) Evaluation of the turbinate hypertrophy by computed tomography in patients with deviated nasal septum. Otolaryngol Head Neck Surg 136(3): 380-384.

23. Holt GR (1999) Biomechanics of nasal septal trauma. Otolaryngol Clin North Am 32(4): 615-619.

24. Pletcher S, Sindwani R, Metson R (2006) Endoscopic orbital and optic nerve decompression. Otolaryngol Clin North Am 39(5): 943-958.

25. Woog JJ, Sindwani R (2006) Endoscopic dacryocystorhinostomy and conjunctivoda-cryocystorhinostomy. Otolaryngol Clin North Am 39(5):1001-1017.
26. Ketcham AS, Han JK (2010) Complications and management of septoplasty. Otolaryngologic clinics of North America 43(4): 897-904.

27. Orlandi RR, Warrier S, Han JK (2010) Concentrated topical epinephrine is safe in endoscopic sinus surgery. Am J Rhinol Allergy 24(2): 140-142.

28. Yanagisawa E, Ho SY (1998) Unintended middle turbinectomy during septoplasty. Ear, Nose \& Throat Journal 77(5): 368

29. Mäkitie A (2000) Postoperative infection following nasal septoplasty. Acta Oto-Laryngologica 120(543):165-166.

30. Yeo NK, Jang YJ (2009) Rhinoplasty to correct nasal deformities in post septoplasty patients. American Journal of Rhinology \& Allergy 23(5): 540-545.

31. Tasca I, Compadretti GC (2011) Nasal growth after pediatric septoplasty at long-term follow-up. American Journal of Rhinology \& Allergy 25(1): e7-12.

32. Lee JJ, Hong SD, Dhong HJ, Chung SK, Kim HY (2019) Risk factors for intraoperative saddle nose deformity in septoplasty patients. European Archives of Oto-Rhino-Laryngology 276(7): 1981-1986.

33. Abdulaziz Qobty, Mohammad Alshareef, Talat Ardi, Ali Alzarei, Ibrahim Sumaily (2019) Impact of Septoplasty on Nasal Allergic Symptoms. Otolaryngology $9(4)$.

\section{(C) () \\ This work is licensed under Creative Commons Attribution 4.0 License}

To Submit Your Article Click Here:

Submit Article
DOI: $10.32474 /$ SJ0.2020.05.000208

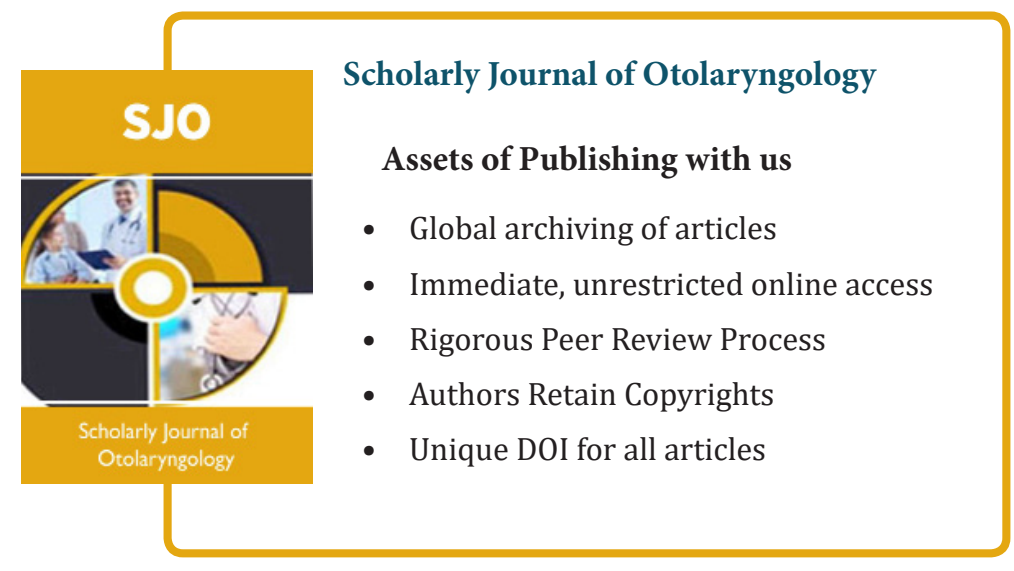

